\title{
QUEEN'S
UNIVERSITY
BELFAST
}

\section{Feminist legal geographies of intimate-image sexual abuse: Using copyright logic to combat the unauthorized distribution of celebrity intimate images in cyberspaces}

Farries, E., \& Sturm, T. (2019). Feminist legal geographies of intimate-image sexual abuse: Using copyright logic to combat the unauthorized distribution of celebrity intimate images in cyberspaces. Environment and Planning A, 51(5), 1145-1165. https://doi.org/10.1177/0308518X18786964

Published in:

Environment and Planning A

Document Version:

Peer reviewed version

Queen's University Belfast - Research Portal:

Link to publication record in Queen's University Belfast Research Portal

Publisher rights

Copyright 2018 SAGE. This work is made available online in accordance with the publisher's policies. Please refer to any applicable terms of use of the publisher.

\section{General rights}

Copyright for the publications made accessible via the Queen's University Belfast Research Portal is retained by the author(s) and / or other copyright owners and it is a condition of accessing these publications that users recognise and abide by the legal requirements associated with these rights.

Take down policy

The Research Portal is Queen's institutional repository that provides access to Queen's research output. Every effort has been made to ensure that content in the Research Portal does not infringe any person's rights, or applicable UK laws. If you discover content in the

Research Portal that you believe breaches copyright or violates any law, please contact openaccess@qub.ac.uk. 


\section{Abstract}

Women's rights are often curtailed online due to the pervasive internet atmosphere of cybermisogyny. Extreme examples include 'image-based sexual abuse', a term which encompasses the non-consensual creation and/or distribution of private sexual images. The harms attached to this phenomenon are well documented. In this paper, we explore how copyright logic, despite its male-centric and property oriented worldview, presents one legal solution to this problem. We assert that Digital Millennium Copyright Act (DMCA) Takedown Notices, a copyright mechanism that notifies websites they are hosting infringing content and requires the prompt removal of the content, represents a novel legal mechanism to force websites to remove image-based sexual abuse from women's online spaces. By using critical discourse analysis to review how DMCA Takedown Notices attempt to provide solutions to the socio-spatial problem of image-based sexual abuse, we argue that copyright can subvert its current leanings to return to its original purpose: supporting creativity. Supporting creativity also helps to protect against the reproduction of gendered harms, from the real world to virtual spaces. This theorization represents not just legal geography but a feminist legal geography, in that it recognizes the internet should be a safe and legal space for women. In endorsing a pragmatic legal solution for women to regulate the sexually violent and nonconsensual distribution of their intimate images online, copyright is one mechanism that affirms women's right to cyberspaces. 


\section{Introduction}

As one avenue for reclaiming the internet as a rightful space for women, we explore how copyright logic responds to misogynistic practices and spaces online. Copyright logic describes a host of international legislation and rules that seeks to balance the way people creatively express ideas, including the images in photographs and videos. It seeks to prevent others from copying, changing, selling or distributing expressed ideas without the permission of the creator. If someone distributes an image without the permission of the creator, the creator is entitled to civil remedies to prevent use and to seek compensation. Thus, while criminal and other civil sanctions are growing against this practice, they can be procedurally victimizing or inaccessible for women. We argue that copyright alternatively offers accessible and pragmatic legal alternatives for women to respond to the sexually violent and nonconsensual distribution of their intimate images online. Copyright, therefore, is a mechanism that affirms womens' right to cyberspaces.

However, Bartow (2006) explains how copyright is currently motivated by malecentric and economic considerations, in so far as it is largely men who utilize copyright solutions to control and retain creative resources, even when these are collaborative processes of women. These power relations and priorities push women's concerns, including ownership and control over private images to domestic and crucially, not legal, spaces. Still, as Bambauer (2013) first queried, subversive opportunities have arisen in the form of Digital Millennium Copyright Act Takedown Notices (henceforth, DMCA Takedown Notices).

Centering our description around the experience of Leslie Jones and other celebrities, we explain how the internet is a socio-spatial environment that amplifies women's experiences of misogyny offline. We argue how the nonconsensual distribution of women's images is an important and timely legal feminist geographic issue which can benefit from 
copyright's activist potential for spatial justice online. We explore DMCA Takedown Notices as a novel copyright mechanism for securing women's spatial sanctity, security, and agency. Using critical discourse analysis, we review 256 DMCA Takedown Notices filed by an American entertainment law firm on behalf of 22 celebrities, a potential digital wunderkammer to help women assert their right to sexual abuse free cyberspaces. We argue that these notices demonstrate how copyright logic, despite normatively relegating women to domestic sphere, still defends their right to exist in virtual spaces. Although the notices reflect normative male centric perspectives of privacy and domesticity, they still seek to subvert dominant paradigms to protect the images according to copyright's original purpose: creativity. They therefore, borrowing from Lefebvre's (1996) framework, have the potentiality to affirm women's right to cyberspaces.

In arguing that women might exercise their right to the internet through copyright interventions in favour of what we call cyberspatial justice, we use here PhillippopoulosMihalopoulos' (2014: i) definition of spatial justice as it pertains to the law, that is 'spatial justice is the struggle of various bodies - human, natural, non-organic, technological - to occupy a certain space at a certain time' (see also, Soja 2010). According to PhillippopoulosMihalopoulos (2014:175), the only way in which law can generate justice: by withdrawing before the demands of justice while retaining its position as the main means in which justice can be achieved. This does not mean that spatial injustice of image-based sexual abuses do not also extend to real and tangible harms that go well beyond the internet into non-virtual spaces - they clearly do. Rather, we echo Bryce and Rutter's (2003) observation that the socio-spatial aspects of the internet are complexly interpenetrated with social spaces offline. For, as geographers including Longhurst (2013: 122) have argued, 'the internet is not a space that is separate or disconnected from the real world'; rather, as Madianou (2005) affirms, the internet changes and mediates the interactions individuals have with each other. 


\section{Part I. Spaces of Cybermisogyny in Celebrity Context}

When Leslie Jones took intimate photos of herself, she was entitled to privacy and dignity, which are established human rights. However, that was not what an anonymous troll was concerned with when they hacked her images and released them online for public observation. A comedian on Saturday Night Live, Jones was invited to star in the wellreceived reboot of the 1980's Ghostbusters film. The film was contentious because some fans of the series did not want the reboot to feature all women protagonists when the originals were all men (Gilbert, 2016). The backlash against Jones, the only black woman on the cast, was particularly fierce. In the summer of 2016, her active Twitter account was subject to a series of sexist and racist slurs. While she contemplated retreating from social media in response, the harassment increased. In August 2016, in a phenomenon described as 'doxing', anonymous trolls hacked her private information and uploaded it online. They shared scans of her passport and driver's license. Even more intrusively, they released her personal intimate images. Gizmodo reported seeing 'multiple nude photographs of Jones, and photos that appear to show the star engaging in sexual acts' (Turton, 2016). In racist contrast, the trolls also uploaded a picture of Harambe, a gorilla who had recently been executed at the Cincinnati zoo when a child fell into its pen. Making good on her threat to withdraw from the online spaces, Leslie Jones took down her website and went silent on Twitter.

This attempt to shame Jones publically with her private and intimate pictures isn't new or unique. It is a form of gendered sexual abuse and harassment online that is prolific, accessible, and can come from any potential group, including former intimate partners, acquaintances, or in her case, anonymous trolls. Indeed, Jones was not the first celebrity to experience this abuse. In the summer of 2014, trolls released the names and photos of 60 celebrities, including Jennifer Lawrence, Kate Upton, and Kirsten Dunst (Serna, 2016). 
Further, quasi- and non- public figures have also experienced these invasions of privacy, including Canadian Judge Lori Douglas, whose superiors required her to submit to ongoing disciplinary hearings after her husband published intimate pictures of her without her permission (Puxley, 2016). This also includes vulnerable members of society, including the story of Amanda Todd, who was 15 years old when she exposed herself online to an anonymous user. When, as part of a campaign of harassment and extortion, that user circulated her topless picture, she was harassed extensively by her school community and eventually committed suicide (BBC, 2017).

\section{Demographic factors and celebrity focus}

This harassment of women online is of course not limited to image-based sexual abuse but is part of a larger cultural phenomenon that includes gendered, heterosexist and racialized stereotyping, objectification, condescension, mansplaining, doxing, and sexual assault and death threats. These various abuses have been well documented (Citron, 2014; LEAF, 2014). Further, while anyone can be the victim of image-based sexual abuse, there are clearly gendered dimensions as research shows that the majority of victims are women (Franks, 2015; O’Connor, 2014) and the majority of perpetrators are men (Henry and Powell, 2016). Other demographic factors are at play as well. As McGlynn (2017:39) notes, men who do not conform to conventional masculine norms or stereotypes are at greater risk. People who identify as lesbian, gay, or bisexual (LGB) are also at a higher risk: 17\% of LGB American internet users have either had an image shared without their consent or have had someone threaten to share an image of them compared to $3 \%$ of heterosexual users (Lenart, Ybarra and Price-Feemey, 2016). One's race or ethnicity is also a risk factor, with black American internet users having a $7 \%$ higher risk factor compared to $3 \%$ of white users (ibid.). To date, there does not appear to be robust data for trans and gender diverse internet users, people of 
color, indigenous people, and people with disabilities; however, one can surmise their higher risk factor given that trans people, for example, report higher likelihoods of sexual harassment offline (Henry, Powell and Flynn, 2017).

Regarding the experience of women, LEAF (2014: 5) describes this online experiences of harassment as 'cybermisogyny,' which they explain:

...encapsulates the diverse forms of gendered hatred, harassment, and abusive behavior directed towards women and girls online. It offers a more nuanced way of describing behaviors often lumped into the catch-all term 'cyberbullying' in mainstream discourse, a term which tends to erase the sexist, racist, homophobic, transphobic, and otherwise discriminatory nature of the behavior and ignores the context of power and marginalization in which it occurs.

We embrace the use of the term cybermisogyny while not losing sight of terms like 'misogynoir' which identifies the 'particular brand of hatred directed at black women in American visual and popular culture' (Bailey, 2010) including Leslie Jones.

Despite the diverse demographic experiences of cybermisogyny outlined above, this paper focuses almost exclusively on celebrity women, a group which tends to be rich and privileged. The reasons are contextual and methodological: in a unique historical occurrence unfortunately referred to as 'the Fappening', a man identified as Ryan Collier uploaded over 500 images of celebrities (nearly all women) that he had retrieved from their email and cloud storage accounts through hacking (Serna, 2016), resulting in 100s of copyright notices being released in response to the pictures. Because of the copyright notices filed as a result of these events, the majority of publically accessible data on the use of copyright to combat cybermisogyny is for the moment available from cases concerning celebrities. While we analyse a subset of these notices, we want to restate that the gendered aspects of online abuse are not limited to the celebrity demographic, and moreover, they are intersectional with race 
and class. As Jones' experience of white supremacy demonstrates, the release of her photos reveals intersectional factors that extend beyond gender discrimination into cybermisogyny. The uploaded photo of Harambe demonstrated it was not just that she was a woman in the reboot it was that she was a black woman. Her targeted harassment on the internet supports Daniels (2009a) assertion that, in addition to gender, race matters just as much online as off.

It is also important to express that celebrity women, despite their relative power, are not shielded from culturally gendered messaging built around the release of their private and intimate images. As Poole (2013) notes, women whose conduct does not conform with traditionally gendered behavioral expectations can be exposed to 'slut-shaming', a cultural practice that seeks to shame them (see also Ringrose and Renold 2012). Thus, discourses which construct celebrities as victims of image-based sexual abuse do so in so far as celebrities do not express their sexuality publically. For those who do, Lawson (2017) has summarized public discourses which often suggest that the celebrities deserved their victimization. Thus, even for privileged celebrities, this abuse has required them to either dismiss their own sexuality or 'be labeled as easy' in normative discourse (Poole, 2013: 232).

\section{Part II. Image-based Sexual Abuse}

There are several names for the form of cybermisogynistic exclusion and forced objectification that trolls inflicted on Jones when they uploaded her private and intimate images into public online space without her consent. McGlynn and Rackley (2017) have conceptualized the term 'image-based sexual abuse' to capture the sexualized violence in the non-consensual creation and/or distribution of private sexual images. This term most effectively captures the behaviors and harms without being reduced to specific motivations. The phenomenon is also often termed 'revenge porn', which Beyens and Lievens (2016: 13) define this 'as the act of distributing photos or videos depicting individuals in sexually 
suggestive or explicit circumstances without consent' (See also Dawkins 2015); Pitcher 2015). However, the Cyber Civil Rights Initiative (n.d.) supports the term 'Nonconsensual Pornography' because, as was the case with Lori Douglas, intimate images aren't always uploaded to extract revenge. Douglas' spouse for example was not seeking revenge but titillation (Puxley, 2016), yet the effects were still devastating for Douglas. There are also financial motives when the victim is famous. For example, the model and actor Emily Ratajkowski had her private photos stolen by anonymous hackers in February 2017, who then tried to sell the images (The Toronto Sun, 2017). Ratajkowksi has denounced the unauthorized release of her intimate images as a violation of her dignity and privacy.

Regardless of motive, or whether the attacker is known to the victim or not, the clear intent is to violate a person's personal autonomy, dignity, and privacy in a sexualized way is a form of sexual assault (LEAF 2014: 13). Image-based sexual abuse situates the person distributing the images in a position of power, where they can maintain coercive control. Experts concur that such acts are grotesquely invasive. Indeed, Jennifer Lawrence also likened the release of her images to a sex crime: 'It is not a scandal. It is a sex crime. It is a sexual violation...It's disgusting. The law needs to be changed, and we need to change' (Kashner, 2014). Similarly, Associate Chief Justice Douglas said of her disciplinary hearings, where panel members viewed the photos without her permission and questioned her on them, was like being sexually assaulted (Puxley, 2016): 'It hurt, hurt, hurt, hurt, hurt like agony when I had to be interviewed by people who had looked at them'.

Further, while many women are victimized by former intimate partners after the relationship terminates (Pitcher, 2015), anonymous hacking also makes women vulnerable to attacks. Hacking has often occurred when individual cloud accounts are targeted with 'bruteforce' attacks, i.e. program scripts that rapidly apply numerous password and username combinations until the correct sequence is located (Greenberg, 2014). Intimate images, which 
may have been automatically saved to the cloud without the users' knowledge, are then accessed by the hackers. When a pair of Kirsten Dunst's photos were leaked, she sent a sarcastic Tweet 'thank you', not to the anonymous hacker, but to iCloud (Cohen et al., 2014). Cloud companies like Apple are ever scrambling to patch security holes accessed by hackers, including individual behavioral changes including encrypted two factor authentication processes as a further source of protection. However, in our rapidly evolving technologically mediated society, information online is vulnerable to exploitation. In the celebrity scandal including Jennifer Lawrence and others, Collier sent emails purporting to be from Apple and Google requesting usernames and passwords. He used this information to steal their photos (Serna, 2016).

\section{Other legal interventions and deficits of extant laws}

Copyright law, including DMCA Takedown Notices, offers a novel intervention into imagebased sexual abuse. In the last five years, legislators and enforcement officers have begun to take image-based sexual abuse more seriously. However, their focus has mainly been in the criminal law sphere. Dawkins (2015) and Franks (2016) itemize a host of domestic and international laws along with domestic proposals for the criminalization of image-based sexual abuse. As of July 2017 in the United States, 38 States have laws that criminalize the distribution of intimate photographs (Franks, 2016). For example Florida criminalizes what it terms 'sexual cyberharassment' by giving a misdemeanor of First Degree, or a Felony of Third Degree for Second or Subsequent violations (Sexual cyberharassment, 2016). See also Texas, which describes the 'Unlawful Disclosure or Promotion of Intimate Visual Material' as a Class A Misdemeanor (Sexual cyberharassment, 2016).

Criminal sanctions have also been applied using penal codes unrelated to image-based sexual abuse. Ryan Collier, who hacked into Jennifer Lawrence's and other celebrity 
accounts plead guilty to one count of gaining unauthorized access to a protected computer to obtain information. He was sentenced to 18 months in a federal US prison (Serna, 2016). Aydin Coban, who attacked Amanda Todd, was convicted in 2017 in the Netherlands for similar actions towards 34 young women and five young gay men (BBC, 2017). He was sentenced to 11 years and will be extradited to Canada to face Canadian charges related to Todd.

Regarding Jones' anonymous attacker, the Department of Homeland Security stated at the time of the attack that it was investigating the hack on an ongoing basis (Levin, 2016). This is an extraordinary measure; most victims of this crime do not receive the attention, resources or support of the Department of Homeland Security. That the Department became involved at all, however, suggests there is a growing level of awareness of the connections between image-based sexual abuse and a states' interest in the bodily security of women.

\section{Copyright as a significant women-lead legal remedy}

Still, the effectiveness of criminalizing image-based sexual abuse varies from state to state. A particular critique has been raised by the Cyber Civil Rights Initiative (Initiative CCR, 2015: np) because 'some revenge porn laws only punish the original perpetrator, but allow others to continue sharing the private images freely.' Further, criminal laws are effective when the perpetrator is known and cannot assist when the attack comes from an anonymous third party. As in sexual assault trials, women too are put on trial (Hengehold 2000), where their voices are 'enframed by the performative nature of legal procedure' (Boyer 1996: 286). They are forced through expensive and lengthy procedural systems of law where the processural endgame often leads to spatial injustice. The systemic justicial responses here seem less concerned with women being granted a right to cyberspaces free of sexual assault from the distribution of their images online, to disciplinary measures aimed at the perpetrators of this 
distribution. Punitive law can further marginalize, oppress, and silence, especially for those without the material and authoritative voice (often men) to challenge the systemic power imbalances within law (Chouinard 1994).

It is therefore important to have further legal recourse when criminal laws are ineffective. Copyright can offer a significant civil remedy here. Criminal laws are driven at the discretion of prosecutors, whereas civil remedies like copyright gives women agency and autonomy, and hence democratization, to lead their own cases (Barnett 2012). Copyright laws can also target third party hosts like websites, who distribute the photographs stolen from an anonymous party. Further, DMCA Takedown Notices are a relatively inexpensive and accessible legal intervention with websites even offering step-by-step instructions on how to submit a notice, opening the process to less economically advantaged people and further intersectional concerns around racism (Urban, Karaganis \& Schofield 2016; Wright, 2017). By focusing on women's legal social cyberspaces it allows us to explore their spatial practices but also to investigate how these cyberspaces are experienced and managed by various agents. Such an approach may reveal forms of oppression or discrimination that a punitive approach might disregard otherwise.

DMCA Takedown Notices are authorized by Section 512 of the Digital Millennium Copyright Act (1988). The section requires hosting services including websites and social media sights, and search engines including Google, to respond expeditiously to notices of copyright infringement in DMCA Takedown Notices by removing hosted content. When a hosting site receives a notice, it must take down the material and notify the alleged infringer that material has been removed. DMCA Takedown Notices typically identify the alleged copyrighted and infringing work and information, contact information for the complaining party or their legal representative, and a statement that the complaining party believes in good faith that the use of the material is infringing. 
Thus, while every legal measure taken against image-based sexual abuse are worth exploring, copyright offers the opportunity for a women-driving and relatively accessible civil law solution.

\section{Part III. Cyberspaces, Neutrality, and Safe Space Optimism}

For internet spaces online, we must acknowledge, as Parker et al. (2016: 3) have aptly observed that that 'spaces are not neutral backgrounds. They are imbued with particular meanings and generate certain behaviors.' In the non-neutral socio-spatial realms of the internet, intimate images circulate without the subject's consent. Thus while the internet is clearly an amorphous structure; with some aspect/spaces being safe for certain people, as Jones' and the others experience demonstrates, internet spaces can also be fora for particularly egregious forms of gender based violence. Indeed, they can amplify the same harassments women experience in non-internet spaces because of the capacity of online communications to reach a much more extensive audience that traditional communications technologies.

Due to the complex interpenetrativeness of sociospaces online and off, the misogynistic invasion of women's intimate sociospatial online forums, are arguably akin to an invasion in geospatial terms. 'Interactions in cyberspace affect interactions in real space and vice versa' (Longhurst, 2013: 122), because the internet is not a space that is separate or disconnected from the real world. Rather, on and offline spaces are inextricably linked (De Jong, 2015). Because 'real space and cyberspace are both experienced through the body' (Longhurst, 2013: 122), the use of Jones' images can 'have real effects, both bodily and physical' on a woman, which are not tangential to how she experiences and lives her everyday life (Henry and Powell, 2015: 765). 
When intimate images are uploaded online, the effects can be devastating. Franks (2015: 2) writes:

In a matter of days, that image can dominate the first several pages of search engine results for the victim's name, as well as being emailed or otherwise exhibited to the victim's family, employers, co-workers, and peers. Victims are frequently threatened with sexual assault, stalked, harassed, fired from jobs, and forced to change schools. Some victims have committed suicide.

McGlynn and Rackley (2017:534) note the loss of 'dignity, privacy and sexual autonomy', which 'combine to constitute a form of cultural harm that impacts directly on individuals, as well as on society as a whole.' Poole (2013: 232) writes that 'the emotional harms caused by slut-shaming [including revenge porn] can follow a woman around for years, damage her self-perception, and possibly cause her either to dismiss her own sexuality or be labeled as easy.' Amanda Todd described anxiety, panic attacks and depression in response to the knowledge that her intimate images were circulating on the internet $(\mathrm{BBC}$, 2017). Similarly, Jennifer Lawrence said, 'I can't even describe to anybody what it feels like to have my naked body shoot across the world like a news flash against my will' (Kashner, 2014). This experience may be akin to what Longhurst \& Balan (2003) describe as bodily abjection: when bodies are used as objects in a particular space, in this case the internet, they become both alluring and repellant as they negotiate spaces of social circulation.

Jones' initial response to the release of her private and intimate images was sociospatial retreat by going silent online. Women before her have taken similar measures. See the experience of Kathy Sierra, a game developer and software programmer who retreated from online life when her images were modified with nooses next to her head (Hess, 2014). Similarly, the Guardian writer, Jessica Valenti, decided to take a break from social media after trolls threatened to rape and kill her five year old daughter (Chasmar, 2016). Valenti 
tweeted 'This morning I woke up to a rape and death threat directed at my 5-year-old daughter. That this is part of my work life is unacceptable.' The retreat from public life behind the private divide reaffirms geographers such as Boyd's (1997) description of a persistent and gendered divide between public and private spaces. Much as street harassment in public spaces acts as a form of discipline on women (Logan, 2015), and can effectively push them back into private spaces, so too has internet harassment pushed women offline. However, it should not be the responsibility of the victim to retreat; shifting any responsibility from the perpetrator onto the victim would simply perpetuate a culture of victim blaming. Nor is permanent retreat online a practical maneuver when our lives are so interlinked with online function. Ash, Kitchin, and Leszczynski (2018) describe how the omnipresence of the internet in the spaces and practices of everyday life fosters a certain dependency.

The spatial aspects of the internet are not just pervasive and dependent, as Madianou (2005) explains, virtual space can become a core component of our character, mediating our identities in almost inextricable ways. Leslie Jones is a stand-up comedian and so has arguably built her career in part due to her social media use. Therefore, while certain women have understandably retreated from life online, not only is it victim blaming to expect this, it is wholly impractical. In September 2016 Jones' returned to Twitter, tweeting (Jones, 2016): 'Thanks to my fans and friends! I'm soooo ok really. And I will always be funny been through a lot in my life and I ALWAYS GET BACK UP'. This is a clear act of resistance from these women: resistance to the disciplining of their bodies online, resistance against being pushed out of the public sphere, and an unwillingness to be reduced to abject bodies online.

Of course, this new form of disciplining of women online is not the affinity coalition that Donna Haraway originally and optimistically envisioned in her Manifesto (1991). 
Haraway hoped that the new communication technologies leading to today's internet would give people the agency to build coalitions based on shared interests. According to Haraway, these described affinity based coalitions would replace the extant tendency to group people based on reductive and socially constructed identity markers, including gender binaries. Instead there would be uniquely safe spaces online for women to congregate and share information and ideas without being reduced to or defined by their gender identity. Haraway's vision was shared enthusiastically by other feminists including geographer Light (1995), who predicted that the internet specifically offered women a greater opportunity for self-expression. Plant (1996) also argued that computer-mediated communications might create potential new liberatory spaces. As Haraway before, Plant (1996) predicted opportune forums, which would blur the traditional distinctions between genders and remove associated constraints. Braidotti (1996) generally concurred, postulating that genderless opportunities would become available to women notwithstanding the gendered digital divide in access.

That was the 1990s. Despite early optimism, and while acknowledging some spaces of the internet are not necessarily sites of misogyny and can have activist potential (Maclean and Maalsen 2013), academics including Franks (2011, 2015; 2012) describes how gendered harassment has not only undermined the progressive social potential of spaces online, the internet has actually served a medium for expanding and amplifying misogyny. Franks (2011, p.255) notes that:

far from being the site of radical gender deconstruction, or a realm of sophisticated reflection on gender roles, or a world offering freedom from the forced objectification of women's bodies, cyberspace instead has become a place (or rather, places) that work in tandem with and reinforces women's unwilling embodiment.

In other words, the structural inequalities and exclusions in offline spaces also have gendered expressions online (Daniels 2009b: 116). 
Nonconsensual release of intimate images imposes on women what feminist work (Franks, 2011: 226) terms an 'unwilling avatar'. Voluntary avatars are the selfrepresentations that people choose to share in cyberspaces include alternative social media and gaming aliases. A voluntary avatar includes the promotional image depicting Jones in a ghostbusting uniform that she chose to include on her Twitter account. Such willing avatars offer the opportunity to 'escape physical limitations, both geographic and bodily' (Franks, 2011: 225). They represent a realization of Haraway's optimism. The unwilling avatar, becomes a tool for male-centric objectification and 'involves invoking individuals' real bodies for the purposes of threatening, defaming, or sexualizing them without consent' (Franks, 2011: 255). This includes hacking into social media accounts or creating an online profile that purports to be the person in question. In Leslie Jones' case, the sexually graphic avatar posted by trolls without her consent included racialized pejoratives. For Jones, her 'feminine body, constructed as aberrant sexual difference, becomes the conduit for gratification and objectification in both geospatial and sociospatial worlds' (Henry \& Powell, 2015: 768). The negative effects on many involved celebrities were palpable; Jennifer Lawrence adeptly described her own experience, saying 'It just makes me feel like a piece of meat that's being passed around for a profit' (Kashner, 2014).

\section{Part IV. Copyright's Activist Potential for Women's Safe Spaces Online}

One way to affirm socialspatial sanctity is to help build safe internet spaces for women through the application of copyright logic. In evaluating copyright's evolving purpose and potential application to the sociospatial problem of image-based sexual abuse, we acknowledge Blomley's (1994: 51) call for investigations that consider 'the manner in which legal practice serves to produce space yet, in turn, is shaped by a sociospatial context.' An investigation into copyright logic makes it clear that copyright practice both produces and is 
shaped by masculine and economic considerations. While there are variations between legal jurisdictions, the definition provided by the US constitution broadly articulates copyright's purpose:

To promote the Progress of Science and useful Arts, by securing for limited Times to Authors and Inventors the exclusive Right to their respective Writings and Discoveries (U.S. Const. art. I, § 8)

Thus, the initial purpose of copyright was to encourage creativity by granting creators the right to control their science or art for a finite period. As copyright practice evolved, however, the normative focus ensured that economic as opposed to creative protections were prioritized for the owners of copyright. This effectively carved out copyright interests that weren't economic. As Tushnet (2014: 2348) notes, 'copyright works as incentive for economically motivated creators; it handles the non-economically motivated poorly.' Bartow (2006) has argued this as well, observing that the works which receive the most courtmandated protection are those that are the most commercially successful.

Bartow (2006) also offers a gendered analysis, describing how masculine concepts of property drive the economic benefits inherent in intellectual property law (2006: 559):

[C]ertain kinds of work, those best suited for industrial commoditization, have been heavily propertized, while other farms of arts and crafts, those that have been relegated to the domestic realm, are less often the subject of rigorous copyright protection or restriction.

Bartow's gendered critique echoes the ways in which feminist geographers such as Boyd (1997) have articulated the persistent divide between economic (traditionally masculine) and domestic (traditionally feminine) spaces. The priority placed on economic creations over domestic creations, is one reason copyright experts might be hesitant to argue for copyright solutions to image-based sexual abuse. If the works previously receiving strong copyright 
protections from the courts received them only because they were a source of profit to powerful masculine and economic interests, then other copyright holders whose works take place in feminine or domestic spheres may be less likely to perceive their art as protectable or worthy of that protection. Works considered worthy might therefore be considered what Blomley (1994) describes as a co-constituted phenomenon between legal practice and the sociospatial context which prioritizes masculine and economic factors. The perception that the more profits a work brings in, the more likely it will receive full copyright protection means that as Bartow (2006: 559) notes:

People who create things for noncommercial purposes may feel that copyright law has nothing positive to offer them. Though their works may be inherently vested with robust incipient copyright protections, without the will or ability to fund the legal activity necessary to enforce these copyrights, it may seem as if copyright protections barely exist at all.

Those works would include feminine, non-economic productions, including private or intimate images, even if the images themselves go on to be circulated in public spheres for economic gain.

Personhood theory further reveals how masculine and economic priorities complicate the potential of copyright to respond to image-based sexual abuse. Personhood theory is widely regarded as giving initial authors absolute, inalienable control over many aspects of their works. As Regan (2009) describes, personhood theory occupies a central place in copyright theory. However, a personhood theory of copyright law, intellectual property law, and indeed property law generally, has traditionally been based to exclude those who are not male, white, or heterosexual. As Hathcock (2017:239) observes 'modern copyright continues to espouse antiquated ideals of acceptable cultural production, to the exclusion of the cultural property of many historically marginalized people groups.' Hathcock (2017) goes on to 
describe how not only feminine, but culturally queer, black and indigenous forms of work fall outside of the personhood protections constructed under copyright logic. Thus, while imagebased sexual abuse seeks to devalue the personhood of women through the capture and or release of intimate images without their consent, women might be pressed to seek solutions from copyright conventions which have also devalued the personhood of women through its normative male-centric and economically focused practices.

Despite these concerns, we are seeing a debate unfold in the literature where certain academics see avenues for copyright recourse to image-based sexual abuse. Bambauer (2014) in particular leads this discussion and has promoted the option of using copyright to protect intimate images by recalling copyrights early and original purpose - protection of creativity irrespective of commercial value. He writes (2014: 2052):

Copyright law holds considerable potential to address the promise and problems of intimate media. The task at hand - encouraging production of consensual media, while constraining sharing without permission — is precisely that for which intellectual property rules are designed.

Bambauer argues that because of creativity, it is a normative ideal for copyright logic to produce and distribute intimate images on consensual terms. While intimate media is not an economic or masculine aspect of copyright's creative ambit, it is the risk of non-consensual distribution, and the resultant reduction of creativity, which threatens that normative practice. Therefore, copyright protection would encourage normative creative output in keeping with copyrights original purposes. Adapting copyright law to protect intimate images is therefore appropriate to the way copyright has evolved to respond to the technological changes in image capture and creation and its concurrent novel expression of an idea.

A significant critic of Bambauer's ideas is Tushnet (2014), who expresses skepticism about copyright as a remedy on practical terms. Tushnet (2014: 2348) argues that 
incentivizing intimacy cannot be compared to incentivizing the creativity within copyrights protection; thus 'the motivations that induce people to create and share intimate images are unlikely to be affected by a change in copyright law, particularly one that both creators and abusive disseminators are extremely unlikely to understand'. Tushnet emphasizes copyright's evolved economic purpose, saying that it provides no real mechanism for communicating its rules to the lay people experiencing infringing behavior in the manner that Jones, Lawrence, Douglas and Todd have experienced. Tushnet (2014: 2346) ultimately argues that there is a 'profound misfit between every aspect of copyright and the interests at issue with respect to stolen intimate images.'

Practically speaking however, comprehension or communication of legal rules, or lack thereof, has not been a barrier to intellectual property legislation or many other laws in the past. One does not need to be a sophisticated party to understand the intricacies of legal requirements to be subject to them. Non-sophisticated proprietors of copyright infringing goods, for example, are still subject to financial penalties. See for example, the 2008 Canadian awarded damages of $\$ 290,000$ for selling counterfeit copies of copyrighted works in the case of Louis Vuitton Malletier S.A. v. 486353 B.C. Ltd., 2008 BCSC 799. Indeed, lay people are typically engaged in the bulk of copyright infringing behavior - see for example the problem of peer-to-peer downloading of copyrighted media.

However, Tushnet's (2014) posited intractability of copyright to respond to women's concerns over their unauthorized distribution of private images reflects a normative position in copyright law. As Delaney (2015) notes, contextual factors complicate how law develops. Developing a protective copyright response will necessarily push against gendered and economic norms built into copyright logic. Thus, when Tushnet (2014) argues that incentivizing intimacy cannot be compared to incentivizing creativity for copyright purposes, this argument may simply echo copyrights masculine and economic norms. However, 
forgiving copyright for reproducing masculinist and economic priorities for legal protection online only supports the sociospatial context from which copyright is both molded from and supportive of. Whereas mobilizing legal mechanisms that enable safe spaces online for women requires legal practice to produce feminist spaces by drawing from pockets of legal expertise. Therefore, much as feminist activism has resisted and reworked the constitutive problems of patriarchy and economic motivation, so too can copyright return from this trend of masculine and commercial protectionism to its original purpose: celebrating creativity. Creativity includes the right of women to safely produce intimate photos and keep them secure from hacking and dissemination online.

As indicated below, we are now seeing non-economically motivated, feminine, and domestic interests lean on copyright logic to imbue internet spaces with safeguards against image-based sexual abuse in much the way Bambauer (2013) queried they might. The concerns attached to copyright logic therefore, which places masculine and economic interests at the centre, do not seem to apply here. Thus, while we recognize the arguments outlined above that copyright on the one hand is clearly a system of legal evaluation that does not tend to afford rights to anyone falling out of the white heterosexual, western, public, and economics-focused ambit, there are still signs that its normative barriers are being circumvented.

Why is this happening? We might consider DMCA Takedown Notices together with the growing literature on feminist material culture studies for an explanation. Bambauer (2013) queried why people didn't submit take down notifications under the US DMCA. The DMCA requires websites to quickly remove unlawful use of copyrighted images from their servers. Cooperating by removing material earns them a 'safe harbor' against further legal action. The safe harbor was originally designed for pirated TV shows, films and music. However, it is coincidentally well suited to image-based sexual abuse. According to strict 
copyright logic, DMCA Takedown Notices should not be available to women if they did not take the intimate photo themselves, as they would not be the creator of the expressive work. However, research has estimated that up to $80 \%$ of nonconsensually distributed intimate images are taken by the subject as 'selfies' (Levendowski 2014: 62). This helps to fill legal gaps particularly in jurisdictions where efforts to criminalize nonconsensually distributed intimate media do so only for victims who have not taken the images themselves (Folderauer 2015: 339). Despite copyright preference for a single 'master mind,' Bambauer (2014) argues that entitlements to co-ownership in situations of image based sexual abuse should be extended to the person captured in the photo as they are part of the creative process. While not tested in litigation, such a conclusion has historical precedent in the UK's Fine Arts Copyright Act 1862, where the 'subject of a photograph might be granted a right of control over the use to which the photograph was put' (Richardson 2017: 63). Further, because DMCA Takedown Notices do not require that victims demonstrate their copyrights in the first instance, victims have filed even though they are not the authors in the strict sense. Regardless, as we will discuss in the next section, DMCA Takedown Notices have been filed in significant numbers on behalf of celebrity women with the potential to be accessibly and democratically normalized for women of non-celebrity status to pursue similar actions as these processes become legally streamlined, universalized, and systematic (Urban, Karaganis \& Schofield 2016).

We argue that this is occurring because there exists a sort of wunderkammer of cultural inclusivity here that is overriding economic, masculine, or paternalistic interests in copyright logic to provide workable solutions to image-based sexual abuse in manner that affirms the personhood of women (Bartlett and Henderson 2013). A wunderkammer, or cabinet of curiosities, was a renaissance aged cabinet used in to hold objects whose categorical boundaries have yet to be defined. It has been employed recently to house novel 
concepts in feminist material culture studies and digital spaces where, for example, different values of masculine material cultures might interplay with feminine material culture (Goggin \& Fowkes-Tobin 2009; Büscher, et al. 2010). Today we can already see an assemblage of actions with in the cultural wunderkammer, as both academics and legal practitioners are now resisting the confinement of copyright protections for economically motivated parties. A DMCA takedown notice is not as Tushnet (2014: 2348) argues a 'concept of authorship-is normatively empty and can be filled any way we want to fill it.' Rather, placed in the wunderkammer alongside image-based sexual abuse, it presents an opportunity to make personhood issues of personal autonomy, dignity, privacy accessible and even liberatory in the tradition of male centric copyright logic. Although stereotypical notions of masculinity and femininity have been naturalized and perpetuated within copyright logic, when women use DMCA Takedown Notices to confront imbalances, they are placing copyright logic tradition of wunderkammer serve to make. It places subversive kick to the gendered hierarchy in copyright which values economic output over domestic privacy and freedom for self-expression.

\section{Part V. A Discursive Review of DMCA Takedown Notices Filed for Celebrities}

Here, we review samples of 256 DMCA Takedown Notices sent to Google Inc. from Lavely \& Singer, an American litigation corporation (Lumen, 2017). We use critical discourse analysis (Hirji, 2014) for deconstructing the type of language used in the notices. This method assesses biases that may be embedded within the discursive sample. It analyses 'opaque as well as transparent structural relationships of dominance, discrimination, power and control as manifested in language' (Wodak, 2008: 10). We use this method to create a structure of meaning regarding women subjected to image-based sexual abuse, focusing less 
on the specific, individual constructions and more on the patterns of construction or the availability of discourses as evidenced across a sample of texts (Sykes et al., 2004).

Civil litigation is normatively private, making it very difficult to access legal documents between parties. However, we gathered the sampled DMCA Takedown Notices via the Lumen Takedown Project database, an independent 3rd party research project studying cease and desist letters concerning online content (Lumen, 2017), that acts for this project as a kind of Wunderkammer for feminist activism within cyberspaces. A project of the Berkman Klein Center for Internet \& Society at Harvard University, Lumen has constructed a database containing millions of cease and desist notices, including DMCA Takedown Notices. we selected notices if they referred to a prominent celebrity, and therefore retrieved 256 DMCA Takedown Notices samples referring to the following 22 celebrities: Actors including Amber Heard, Jennifer Lawrence, Kate Upton, Kirsten Dunst, Yvonne Strahovski, Megan Boone, Meaghan Good, Rachel Nichols, Scarlett Johansson, Kat Dennings, Abigail Spencer, Vanessa Hudgens, Zoe Kazan, Blake Lively, Lake Bell and Krysten Ritter; the Olympian McKayla Maroney; Models including Carolyn Murphy and Emily Ratajkowski; Musicians including Travis Barker and Avril Lavigne; and Director and Screen Writer Christopher Landon. All of these celebrities have had private photos hacked and illegally posted online. There was no indication from the database that they represented Leslie Jones.

In lieu of NVivo, we used the multiple-field Lumen search engine. We searched for DMCA Takedown Notices filed from 3 January 2014 to 15 January 2017 (just before the mass theft of celebrity images up to the initial submission of this paper). This search revealed 256 DMCA Takedown Notices, most of which were boilerplates. It was the specificity of language that was of was of most relevance and therefore each example below was selected for after discourse analysis of each of the 256 filed notices, from which we looked for unique 
files. The keywords sorted for were: private; privacy; celebrity; nude; stolen; intentional; hacked; unauthorized; image; and photograph. We deconstructed the type of language used by assessing gendered sociocultural biases embedded within. We chose language that placed an emphasis on the public/private divide per Boyd (1997) and that, despite Bartow's (2006) and Tushnet's (2014) critiques, sought to protect domestic and non-commercial realms. We considered any language that argued for protection irrespective of the image's profitability and highlighted Bambauer's (2014) suggestion that using copyright protection promotes creativity. Some of the notices clearly relied on boilerplate arguments, i.e. the repetitive use of arguments for each individual complainant. The following five texts are notable (our emphasis in bold) of the kind of creativity potential within copyright.

\section{Jennifer Lawrence}

... We are litigation counsel for actress Jennifer Lawrence. Our client holds all rights, title, interest and copyright to certain private photographs, capturing herself in private moments in private locations (collectively, the "Photos"). We are writing with respect to our client's claims arising from repeat violations of copyright laws, and gross invasions of privacy, as relates to the unauthorized online posting, linking to, disseminating and/or publishing of the previously unpublished stolen copies of my client's copyright protected Photos by your service's users (the "User"). Unauthorized stolen copies of our client's previously unpublished private Photos appear at and are hosted and contained on your server and/or system (your "System")...(Lavely \& Singer PC, n.d.)

This notice for Lawrence argues for her rights to privacy under copyright law. It describes the release of her private photos as a 'gross invasion.' These lexical choices focused on defending Lawrence's body as reserved for the domestic realm, which emphasized a 
public/private divide. The choices push against the misogynist internet objectification that constructs women's bodies as conduits for gratification. They also normatively afford copyright power to the nonindustrial and domestic realms of intimate photos. Male-centric influence is apparent given that the lexical emphasis on saving Lawrence from public exposure did not include a description of what Lawrence wanted herself, but instead constructed her body as private and therefore improper for public consumption. However, the intervention leans against the arguments of Tushnet (2014) and Bartow (2006) that copyright is motivated by male-centric and economic considerations.

\section{Kirsten Dunst}

We are litigation counsel for actress Kirsten Dunst. ...THE ENTIRETY OF THE

BLOG $<$ CELEBRITYICLOUDHACKEDPHOTO.BLOGSPOT.COM $>$ IS

OPERATED FOR THE SOLE PURPOSE OF MASS COPYRIGHT

INFRINGEMENT, SPECIFICALLY FOR THE INTENTIONAL AND KNOWING DISSEMINATION OF HACKED STOLEN PRIVATE NUDE/SEMI-NUDE PHOTOS OF CELEBRITIES, INCLUDING NUDE IMAGES OF UNDERAGE MINORS.... (Lavely \& Singer PC, n.d.)

Like Lawrence, this notice on behalf of Dunst reflects lexical choices focused on a right to privacy under copyright law. The lexical choices describe Dunst's photos as 'stolen private nude...images' which again emphasizes that celebrity women's nude bodies are necessarily private objects which must be restricted to the domestic realm through protections including copyright. While there is a focus on the intentions of the disseminators of the intimate images - see use of the terms 'intentional and knowing' - the desires of Dunst herself are not emphasized in the claim. Still, there is no articulated emphasis on economic motivation. 
Dunst body is constructed a copyrightable artifact despite its relegation to the domestic realm.

\section{Amber Heard}

... The original works are previously unpublished, private photographs of AMBER

HEARD ... EVERY SINGLE IMAGE THAT APPEARS ON THE SUBMITTED

LINK PAGE IS A STOLEN COPYRIGHT PROTECTED IMAGE. ... (Lavely \& Singer PC, n.d.)

For Heard, the upper case discursive emphasis on stolen copyrighted image reflects strong protectionist and masculinist language of control and power. Implicit in the lexical choices are that Heard's body is meant to be controlled for private and not public consumption. Such strong protectionist language troubles the arguments that male centric motivations are also economic motivations. It instead favours Bambauer's argument that a normative ideal for copyright logic is intimate creativity through the production and distribution of intimate images.

\section{McKayla Maroney}

... We are litigation counsel for young Olympian McKayla Maroney. We have become aware of unauthorized copies of stolen private photos of our client, which capture her in a state of undress in private moments, taken while she was an underage minor ... (Lavely \& Singer PC, n.d.) 
Lexical choices were made by Lavely \& Singer to portray Maroney’s experience as particularly egregious as her photos were disseminated as an underage minor. The emphasis on saving Maroney from unauthorized public exposure did not include a description of what Maroney herself wanted but rather constructed her body as improper for public consumption particularly because she was underage.

\section{Scarlett Johansson}

...A copy of a stolen highly personal and private copyright protected photograph (registered with the US Copyright Office) of our client Scarlett Johansson, in which she captures herself self-posing in the privacy of her own home in a state of undress and/or topless (the "Photo(s)") .... (Lavely \& Singer PC, n.d.)

Like the other samples, Johansson's undressed body is described as necessarily private object, which copyright logic must work to keep safe within the domestic realm. Further, Johansson is still framed discursively as private; there is no normative shaming involved of their decisions to take the photographs. Rather, the emphasis is on her creative production, a copyrightable endeavor, which favours lexically the safety of women in their creative domestic endeavours.

Reviewed together, the samples of the DMCA Takedown Notices show that the typical lexical choices included 'private', 'gross invasion', 'privacy', 'protected', and 'state of undress'. These terms created the women's bodies themselves as copyrighted property, a form of bodily abjection that is arguably male-centric. The terms focused on defending these women's bodies as objects reserved for the domestic realm, particularly if the women were a minor (text that was consistently presented in uppercase). The emphasis on saving these 
women from public exposure did not include a description of what the women themselves wanted but rather constructed their bodies as improper for public consumption, particularly if they were young.

This description in these discursive samples of the women's bodies as necessarily restricted to private or domestic realms, with no argument in favour of economic attributes of the images, troubles Bartow (2006) and Tushnet's (2014) description of copyright law as male centric and economically motivated. While Bartow (2006) would surely agree that there is strong protectionist, masculine language of power and control, implying that women's bodies are meant to be privately and not publically consumed, the patterns of constructed meaning here situate copyright as an appropriate mechanism for private and domestic disputes. They support Bambauer's (2013) assertion that copyright's original purpose creative expression - is an asset in of itself and independent of masculine economic motivations. Furthermore, while women are still framed discursively as private, there is no normative shaming involved of their decisions to take the photographs. Rather, the emphasis is maintaining safe virtual spaces for women online through legal processes as opposed to the punitive path of criminal law.

The efficacy of this copyright mechanism remains unclear however, and does not disprove Bartow (2006) and Tushnet's (2014) assertions that copyright protections are most easily afforded to economically motivated and commercially successful actors. The use of DMCA Takedown Notices for copyright infringements online generally has become normative; Google's Transparency Report (2017) indicates that from Dec 14, 2016 to Jan 14, 2017, 64 million URLs were removed. It is not a complete solution; new websites hosting the intimate images emerge just as others remove them. Yet research shows that the take down does result in decreased file availability in the short term (Lauinger et al., 2012). When websites become reputationally noteworthy for hosting copyright infringing material, this 
arguably makes them more susceptible to blocking injunctions from the court, which precludes them from providing access to copyrighted material of litigants.

There are also limitations to copyright logic as a path for the right to the internet. Civil legal remedies are typically slow and retroactive; the violence has already occurred. Moreover, they are often financially prohibitive mechanisms and unavailable to women who are not affluent or otherwise powerful celebrities. However, numerous sites are appearing online that describe relatively accessible steps for women themselves to rapidly draft and file DMCA Takedown Notices to websites (Quinn, 2009). Of course, for websites that refuse to take down the images in response to DMCA Takedown Notices, the next step is court litigation, a prohibitively expensive mechanism. Only four percent of law suits go to trial, so we have not yet been provided with a legal example of how this matter would resolve in court. Lavely \& Singer threatened in 2014 to seek 100 million in damages from Google Inc. for Google's lethargy in removing intimate media when it appeared online (Spangler, 2014). However, it appears no suit was ever filed, despite several of Lavely's celebrity clients' intimate photos still appearing in Google searches. Of note, we were not able to locate Leslie Jones' private photos in a Google search. We suspect that between the 2014 and 2016, the time lapse between when Jennifer Lawrence and Leslie Jones's photos were uploaded, Google Inc. has become more proficient in removing these images at the outset. The threat of copyright litigation has perhaps significant influence to shift cultural standards in allowing these images to proliferate. Thus, through a feminist legal geographic analytic, these cases illustrate how celebrities like Jones, but also women generally, can use copyright logic as a means to combat cybermisogyny and achieve spatial justice online. Our theorization therefore represents not simply a legal geography, but a feminist legal geography because we are demonstrating an ongoing struggle to create legal rights for women for their own bodily integrity in multiple spaces, including online. 


\section{Conclusion}

While we acknowledge that there is a paradoxical potential to copyright logic by using malecentric legal remedies (and we recognize the limitations of copyright law especially in the cases where the image is taken by the abuser) in part can overcome these issues through material cultural interventions like wunderkammer: a subversive way to employ copyright law despite its male centric leanings (Bartlett A and Henderson 2013). Taking inspiration from the novel way DMCA Takedown Notices are used to protect non-consensually distributed intimate images, we might further search for ways to revamp copyright logic to reassert its original priority: protecting creativity. This priority would help women to exist bodily online unencumbered by gendered prejudice and cybermisogyny. The reassertion of copyright's original purpose may therefore be a form of legal cyberspatial justice that will assist women to operate virtually according to their own perspectives and inclinations. This is not just a feminist geographic issue, but a feminist legal geographic issue: copyright logic can help women to claim the internet as a safe and legal space; it can help concretize their right to the internet.

\section{References}

Ash J, Kitchin R and Leszczynski A (2018) Digital turn, digital geographies? Progress in Human Geography 42(1): 25-43.

Bailey M (2010) They aren't talking about me... Crunk Feminist Collective, 14th March. Available from: http://www.crunkfeministcollective.com/2010/03/14/they-arent-talkingabout-me/ (accessed 12 January 2017).

Bambauer D (2013) Beating revenge porn with copyright. INFO LAW, 25th January. Available from: https://blogs.harvard.edu/infolaw/2013/01/25/beating-revenge-pornwith-copyright/ (accessed 15 January 2017).

Bambauer DE (2014) Exposed. Minnesota Law Review 98: 2025-2102.

Barnett C (2012) Situating the geographies of injustice in democratic theory. Geoforum 43(4): 677-686.

Bartlett A and Henderson M (eds.) (2013) Things that Liberate: An Australian Feminist 
Wunderkammer. Newcastle: Cambridge Scholars Publishing.

Bartow A (2006) Fair use and the fairer sex: Gender, feminism, and copyright law. Journal of Gender, Social Policy \& the Law 14(3): 551-584.

BBC (2017) Amanda Todd case: Accused Dutchman jailed for cyberbullying. BBC News, 16 March. Available from http://www.bbc.com/news/world-us-canada-39295474 (accessed 5 February 2018).

Beyens J and Lievens E (2016) A legal perspective on the non-consensual dissemination of sexual images: Identifying strengths and weaknesses of legislation in the US, UK and Belgium. International Journal of Law, Crime and Justice 47(April): 31-43.

Blomley NK (1994) Law, Space, and the Geographies of Power. New York: Guilford Press. Boyd SB (ed.) (1997) Challenging the Public/Private Divide: Feminism, Law, and Public Policy. Toronto: University of Toronto Press.

Braidotti R (1996) Cyberfeminism with a difference. In: Peters MA, Olssen M, and Lankshear C (eds), Futures of Critical Theory, Lanham: Rowman \& Littlefield, pp. 239-260.

Bryce J and Rutter J (2003). Gender dynamics and the social and spatial organization of computer gaming. Leisure Studies, 22(1), 1-15.

Büscher M, Kompast M, Lainer R and Wagner I (2010) The Architect's Wunderkammer: Aesthetic pleasure and engagement in electronic spaces. Digital Creativity, 10(1), 1-17.

Chasmar (2016) Jessica Valenti, Guardian columnist, quits Twitter over 'rape and death threat' against daughter. The Washington Times, 27th July. Available from: http://www.washingtontimes.com/news/2016/jul/27/jessica-valenti-guardian-columnistquits-Twitter-o/ (accessed 15 January 2017).

Citron DK (2014) Hate Crimes in Cyberspace. Cambridge: Harvard University Press.

Cohen S, O’Neill N and Tacopino J (2014) Kirsten Dunst on nude photo hack: 'Thank you iCloud'. Page Six. Available from: http://pagesix.com/2014/09/02/kirsten-dunst-onnude-photo-hack-thank-you-icloud/ (accessed 12 January 2017).

Daly-Goggin M and Fowkes Tobin B (eds) (2009) Women and Things, 1750-1950, Farnham: Ashgate.

Daniels J (2009a) Cyber Racism: White Supremacy Online and the New Attack on Civil Rights. Lanam: Rowman \& Littlefield.

Daniels J (2009b) Rethinking cyberfeminism(s): Race, gender, and embodiment. Women's Studies Quarterly 37(1/2): 101-124.

Davidson J, Bondi L and Smith M (eds) (2016) Emotional Geographies. New York: Routledge.

Dawkins JTI (2015) A dish served cold: The case for criminalizing revenge pornography. Cumberland Law Review 45(2): 395-447.

De Jong A (2015) Using facebook as a space for storytelling in geographical research. Geographical Research 53(2): 211-223.

Delaney D (2014) Legal geography I: Constitutivities, complexities, and contingencies. Progress in Human Geography 39(1): 96-102.

Delaney D (2015) Legal geography II: Discerning injustice. Progress in Human Geography 40(2): $1-8$.

Digital Millennium Copyright Act (1988) United States.

Folderauer, K. M. (2015) Comments: Not all is fair (use) in love and war: Copyright law and revenge porn. University of Baltimore Law Review, 44(2) 321-344.

Franks MA (2017) 'Revenge porn' reform: A view from the front lines. Florida Law Review, forthcoming University of Miami Legal Studies Research Paper No. 16-43.

Franks MA (2011) Unwilling avatars: Idealism and discrimination in cyberspace. Columbia Journal of Gender and Law 20(2): 224-261. 
Franks MA (2015) Drafting An Effective 'Revenge Porn' Law: A Guide for Legislators. Available from: https://papers.ssrn.com/sol3/papers.cfm?abstract id=2468823 (accessed 4 January 2017).

Franks MA and Pdf H (2012) Sexual harassment 2.0. Maryland Law Review 71(3): 655-704. Gilbert S (2016) Was 2016 Ready for an all-female Ghostbusters? The Atlantic, 19th July. Available from: http://www.theatlantic.com/entertainment/archive/2016/07/ghostbustersbacklash/491834/ (accessed 12 January 2017).

Google (2017) Transparency report. Available from: https://www.google.com/transparencyreport/removals/copyright/\#glance (accessed 15 January 2017).

Greenberg A (2014) The police tool that pervs use to steal nudes pics from Apple's iCloud. Wired. Available from: https://www.wired.com/2014/09/eppb-icloud.

Haraway D (1991) Simians, Cyborgs, and Women: The Reinvention of Nature, New York: Routledge.

Hathcock A (2017) Confining cultural expression: How the historical principles behind modern copyright law perpetuate cultural exclusion American University Journal of Gender, Social Policy \& the Law 25(3): 239-260.

Henry N Powell A and Flynn A (2017) Not just 'revenge pornography': Australians' experiences of image-based abuse. A Summary Report. Melbourne: RMIT University.

Henry N and Powell A (2016) Sexual violence in the digital age: The scope and limits of criminal law. Social \& Legal Studies 24(4): 397-418.

Henry N and Powell A (2015) Embodied harms: Gender, shame, and technology-facilitated sexual violence. Violence Against Women 21(6): 758-779.

Hess A (2014) Why women aren't welcome on the internet. Pacific Standard, 6th January. Available from: https://psmag.com/why-women-aren-t-welcome-on-the-internetaa21fdbc8d6\#.mfkgq35m4 (accessed 15 January 2017).

Hirji F (2014) The colour of difference: Race, diversity, and journalism in Canada. 4th ed. In: Shade LR (ed.), Mediascapes: New Patterns in Canadian Communication, Toronto: Nelson Education, pp. 390-408.

Initiative CCR (2015) Infographic: The anatomy of an effective revenge porn law. Cyber Civil Rights Initiative. Available from: https://www.cybercivilrights.org/anatomyeffective-revenge-porn-law/ (accessed 10 March 2017).

Initiative CCR (n.d.) Frequently asked questions. Cyber Civil Rights Initiative. Available from: https://www.cybercivilrights.org/faqs/.

Jones L (2016) Thanks to my fans and friends! I'm soooooo ok really. And I will always be funny been through a lot in my life and I ALWAYS GET BACK UP! Twitter, 4th September. Available from: https://Twitter.com/lesdoggg/status/772486372800270336 (accessed 12 January 2017).

Kashner S (2014) Both huntress and prey. Vanity Fair, 20th October. Available from: http://www.vanityfair.com/hollywood/2014/10/jennifer-lawrence-photo-hacking-privacy (accessed 14 January 2017).

Lauinger T, Szydlowski M, Onarlioglu K, et al. (2012) Clickonomics: Determining the effect of anti-piracy measures for one-click hosting. Working paper, Northeastern University. Available from: https://www.internetsociety.org/sites/default/files/07_1_0.pdf (accessed 15 January 2017).

Lavely \& Singer PC (n.d.) DMCA (Copyright) Complaint to Google - Dunst. Lumen. Available from: https://lumendatabase.org/notices/2026057 (accessed 12 January 2017).

Lavely \& Singer PC (n.d.) DMCA (Copyright) Complaint to Google - Heard. Lumen . Available from: https://lumendatabase.org/notices/2041479 (accessed 12 January 2017). 
Lavely \& Singer PC (n.d.) DMCA (Copyright) Complaint to Google - Lawrence. Lumen. Available from: https://lumendatabase.org/notices/2020593 (accessed 12 January 2017).

Lavely \& Singer PC (n.d.) DMCA (Copyright) Complaint to Google - Maroney. Lumen. Available from: https://lumendatabase.org/notices/1981193 (accessed 12 January 2017).

Lavely \& Singer PC (n.d.) Photos DMCA (Copyright) Complaint to Google - Johansson. Lumen. Available from: https://lumendatabase.org/notices/209571 (accessed 12 January 2017).

Lawson CE (2017) Innocent victims, creepy boys: discursive framings of sexuality in online news coverage of the celebrity nude photo hack. Feminist Media Studies Online first. http://dx.doi.org/10.1080/14680777.2017.1350197

Lefebvre H (1996) Writing on Cities. In: Kofman E and Lebas E (eds), Cambridge: WileyBlackwell., pp. 63-184.

Lenart A, Ybarra M, Price-Feemey, M (2016) Nonconsensual image sharing: One in 25 Americans has been a victim of 'revenge porn' Centre for Innovative Public Health Research and Data\&Society Research Institute. Available from: https://datasociety.net/pubs/oh/Nonconsensual_Image_Sharing_2016.pdf (accessed 2 February 2018).

Levin S (2016) Homeland security has 'open investigation' into Leslie Jones hacking. The Guardian, 25th August. Available from:

https://www.theguardian.com/technology/2016/aug/25/homeland-security-leslie-joneshacking-investigation (accessed 14 January 2017).

Levendowski, A. (2014) Using copyright to combat revenge porn. NYU Journal of

Intellectual Property \& Entertainment Law, 3(3), 422-426.

Light J (1995) The Digital Landscape: New space for women? Gender, Place \& Culture 2(2): $133-146$.

Logan LS (2015) Street harassment: Current and promising avenues for researchers and activists. Sociology Compass 9(3):196-211.

Longhurst R (2013) Stretching mothering: Gender, space and information communication technologies. HAGAR Studies in Culture Policy and Identities 11(1): 121-138.

Longhurst R and Balan N (2003) Bodies: Exploring fluid boundaries. Canadian Journal of Communication 28(4): 479-482.

Lumen (2017) About: Lumen. Lumen. Available from: https://lumendatabase.org/pages/about (accessed 12 January 2017).

Louis Vuitton Malletier S.A. v. 486353 B.C. Ltd., 2008 BCSC 799.

McGlynn C and Rackley (2017) More than 'revenge porn': Image-based sexual abuse and the reform of Irish Law. Irish Probation Journal 14: 38- 51.

Madianou M (2005) Mediating the Nation: News, Audiences and the Politics of Identity. London: UCL Press.

Mclean J and Maalsen S (2013) Destroying the joint and dying of shame? A geography of revitalised feminism in social media and beyond. Geographical Research 51(3): 243256.

O'Connor L (2014) Celebrity nude photo leak: Just one more reminder that privacy does not exist online and legally, there's not much we can do about it. GGU Law Review Blog, 21st October. Available from: http://digitalcommons.law.ggu.edu/ggu_law_review_blog/30/(accessed 13 January 2017).

Pain R and Staeheli L (2014) Introduction: Intimacy-geopolitics and violence. Area 46(4): 344-347.

Parker CM, Garcia J, Philbin MM, et al. (2016) Social risk, stigma and space: Key concepts for understanding HIV vulnerability among black men who have sex with men in New 
York City. Culture, Health \& Sexuality 1058(December): 1-15.

Pitcher J (2015) The state of the states: The continuing struggle to criminalize revenge porn. Brigham Young University Law Review 2015(5): 1435-1466.

Plant S (1996) On the matrix: Cyberfeminist simulations. In: Shields R (ed.), Cultures of the Internet: Virtual Spaces, Real Histories, Living Bodies, London: Sage, pp. 170-183.

Phillippopoulos-Mihalopoulos A (2014) Spatial Justice: Body, Lawscape, Atmosphere. London, Routledge.

Poole E (2013). Hey girls, do you know? Slut-shaming on the internet needs to stop. Universtiy of San Francisco Law Review 48: 221 - 232.

Puxley C (2016) Former Manitoba judge compares disciplinary hearing to 'torture'. CBCnews Manitoba, 5th January. Available from: http://www.cbc.ca/news/canada/manitoba/former-manitoba-judge-comparesdisciplinary-hearing-to-torture-1.3390836 (accessed 12 January 2017).

Quinn G (2009) Sample DMCA Take Down letter. IPWatchdog.com. Available from: http://www.ipwatchdog.com/2009/07/06/sample-dmca-take-down-letter/id=4501/ (accessed 12 January 2017).

Regan KM (2009) Downloading personhood: A Hegelian theory of copyright law. Canadian Journal of Law and Technology 7(1): 1 - 40.

Richardson M (2017) The Right to Privacy: Origins and Influence of a Nineteenth-Century Idea. Cambridge: Cambridge University Press.

Ringrose J and Renold E (2012) Slut-shaming, girl power and 'sexualisa- tion': Thinking through the politics of the International SlutWalks with teen girls. Gender and Education 24(3): 333-43.

Serna, J (2016). Man convicted of hacking Gmail and iCloud accounts of at least 30 celebrities in L.A.. Los Angeles Times, 28th September. http://www.latimes.com/local/lanow/la-me-ln-phishing-scam-conviction-20160928snap-story.html (Accessed 02 February 2018).

Soja EW (2010) Seeking Spatial Justice. Minnesota: University of Minnesota Press.

Spangler T (2014) Google threatened with $\$ 100$ million lawsuit over hacked celeb photos. Variety. Available from: variety.com/2014/digital/news/google-threatened-with-100million-lawsuit-over-hacked-celeb-photos-1201319374/ (accessed 12 January 2017).

Sykes CM, Willig C and Marks DF (2004) Discourses in the European Commission's 19962000 health promotion programme. Journal of Health Psycholog 9(1): 131-141.

The Toronto Sun (2017) Nude photos of Emily Ratajkowski hacked. 19th February. Available from: http:/www.torontosun.com/2017/02/19/nude-photos-of-emilyratajkowski-hacked (accessed 02 February 2017).

Turton W (2016) Leslie Jones hacked, nude photos leaked. Gizmodo, 24th August. Available from: http://gizmodo.com/leslie-jones-reportedly-hacked-nude-photos-leaked1785696160 (accessed 3 January 2017).

Tushnet R (2014) How many wrongs make a copyright? Minnesota Law Review: 2346-2374.

Urban J, Karaganis J and Schofield BL (2016) Notice and Takedown in Everyday Practice. New York: American Assembly.

LEAF (2014) Using and Strengthening Canadian Legal Responses to Gendered Hate and Harassment Online. Vancouver: West Coast LEAF. Available from: http://www.clicklaw.bc.ca/resource/2867 (accessed 12 January 2017).

Wodak R (2008) Critical discourse analysis: History, agenda, theory and methodology. In: Methods of Critical Discourse Analysis, London: Sage, pp. 1-33.

Wright CE (2017) Copyright Carolyn E. Wright, Esq. NPPA. Available from https://nppa.org/page/5617 (accessed 13 January 2017) 
